\title{
Использование отработанного растительного масла для получения древесных композитов
}

\author{
(C) 2021 Дмитренков А.И., Ходосова Н.А., Боровской А.М., \\ Недзельская Е.А., Заяц В.В. \\ Воронежский государственный лесотехнический университет имени Г.Ф. Морозова, Воронеж
}

Поступила в редакцию 9.10.2020 г.

DOI: $10.17308 /$ sorpchrom.2021.21/3228

На предприятиях пищевой индустрии в больших количествах образуются отработанные растительные масла, которые остаются после приготовления различных пищевых продуктов. Эти отходы масел плохо утилизируются и загрязняют окружающую среду. В тоже время в промышленности и быту не уменьшается интерес к натуральной древесине, как природному возобновляемому материалу. Однако присущие природной древесине недостатки требуют её модификации различными составами. В работе исследованы свойства древесины берёзы, пропитанной составами на основе отработанного растительного масла. Для пропитки древесины применяли использованное после приготовления пищи рафинированное подсолнечное масло. В качестве наполнителя применяли древесную муку хвойных пород древесины и сиккатив на основе солей металлов. Пропиточный состав с сиккативом и наполнителем нагревали до заданной температуры, в который помещали образцы и выдерживали в течение определенного времени, затем переносили в пропиточный состав, имеющий температуру окружающей среды, где пропитка проходила в течение такого же времени. Пропитку осуществляли способом «горяче-холодных ванн». Свойства древесины контролировали по изменению таких показателей как водопоглощение, разбухание в радиальном и тангенциальном направлениях, а также краевого угла смачивания поверхности древесины. Пропиточные составы на основе отработанного растительного масла не имеет запаха и обладает экологической безопасностью для человека и животных. Отмечено, что использование растительного масла как чистого, так и отработанного, существенно улучшает показатели водостойкости натуральной древесины. Водопоглощение обработанной древесины после 1 суток нахождения в воде снижается в три раза, а после 30 суток испытаний - более чем в два раза по сравнению с необработанной древесиной. Показано, что наиболее оптимальным пропиточным составом на основе отработанного растительного масла для древесины березы является состав, содержащий $1 \%$ древесной муки и 3 \% сиккатива. Таким образом, обработка древесины березы составами на основе отработанного растительного масла, позволяет не только утилизировать отходы производства, но и улучшить свойства древесины, такие как водопоглощение, разбухание в тангенциальном и радиальном направлениях.

Ключевые слова: древесина берёзы, модификация, пропитка, водопоглощение, разбухание, краевой угол смачивания, растительное масло.

\section{Введение}

На предприятиях пищевой индустрии в больших количествах образуются отработанные растительные масла, которые остаются после приготовления различных пищевых продуктов. В основном это рафинированное подсолнечное масло. Эти отходы масел плохо утилизируются и попадают в городскую канализационную систему, загрязняя окружающую среду и осложняя работу очистных сооружений. Они затрудняют жизнедеятельность аэробных бактерий, используемых для переработки сточных вод, что мы и наблюдали прошедшим летом. По- 
этому актуальной является задача утилизации и использования отработанных растительных масел.

В тоже время в промышленности и быту не уменьшается интерес к натуральной древесине, как природному возобновляемому материалу. Это связано с ужесточением экологических требований к применяемым материалам и ограниченности других не возобновляемых ресурсов. Однако присущие натуральной древесине недостатки, особенно способность впитывать воду и другие жидкости, требуют её модификации различными веществами. Эффективными пропиточными материалами, применяемыми для модификации натуральной древесины, являются растительные масла и их отходы.

\section{Теоретическая часть}

Для модификации и защиты натуральной древесины используются самые разнообразные вещества и составы.

В работе [1] показана перспективность использования олеиновой кислоты для защитной обработки древесины малоценных пород. Олеиновая кислота составляет основу таких растительных масел как подсолнечное, оливковое и других. Предлагаемая технология модифицирования древесины олеиновой кислотой обладает экологической безопасностью, позволяет придать изделиям на ее основе высокие декоративные свойства и повысить устойчивость к атмосферным воздействиям.

Разработаны [2-3] составы для пропитки древесины берёзы, включающие отработанное моторное масло и древесную муку. Основу разрабатываемой пропиточной композиции выбирали из четырёх образцов отработанных масел: моторного, трансмиссионного, кукурузного, подсолнечного. Предлагаемые составы для пропитки древесины позволяют уменьшить её водопоглощение и разбухание в тангенциальном и радиальном направлениях.
Авторами [4-7] разработаны безопасные составы для обработки древесины на основе силоксанов, которые после нагревания и химического взаимодействия с компонентами древесного вещества образуют на поверхности древесины эффективное водоотталкивающее покрытие.

В связи с ужесточением экологических требований к композитным материалам на основе древесины, используемым в строительстве и быту, активно проводятся исследования по разработке пропиточных составов на основе льняного, подсолнечного и других растительных масел [8-10].

В работах [11-13] исследована возможность применения отработанных растительных масел для модификации и защитой обработки древесины. Показано, что водопоглощение древесины берёзы, пропитанной отработанными кукурузным и подсолнечным маслами, было значительно ниже, чем натуральной древесины. Наилучшим показателем по разбуханию обладает древесина берёзы, пропитанная составом на основе подсолнечного масла [11].

В промышленности отработанные растительные масла используют в качестве биотоплива для дизельных двигателей [14], в качестве пластифицирующих добавок в строительной индустрии [15].

Целью данной работы является исследование свойств древесины берёзы, модифицированной различными составами на основе отработанного растительного масла с целью улучшения её свойств.

\section{Экспериментальная часть}

Для пропитки готовили образцы древесины березы размером 20 х 20 мм в радиальном и тангенциальном направлениях, высотой вдоль волокон 10 мм. Пропитку осуществляли методом «горче-холодных ванн». Для пропитки древесины применяли использованное после приготовления пищи рафинированное подсолнечное масло. В качестве наполнителя применяли древесную муку хвойных по- 
род древесины и сиккатив на основе солей металлов. Пропиточный состав с сиккативом и наполнителем нагревали до заданной температуры, в который помещали образцы и выдерживали в течение определенного времени, затем переносили в пропиточный состав, имеющий температуру окружающей среды, где пропитка проходила в течение такого же времени.

Оценку эффективности пропиточных составов проводили по следующим показателям: водопоглощение ГОСТ 16483.20-72 «Древесина. Метод определения водопоглощения», разбухание в тангенциальном и радиальном направлениях. Количество пропиточного состава в древесине определяли гравиметрическим методом по разности масс до и после пропитки ГОСТ 20022.6-93.

При определении водопоглощения образцы высушивали при $103^{\circ} \mathrm{C}$ в бюксах до абсолютно сухого состояния, после чего опускали их под эксикаторную вставку и наливали дистиллированную воды выше уровня вставки. Количество поглощенной влаги вычисляли по формуле:

$$
W=\frac{m_{n}-m_{1}}{m_{1}-m} 100 \%
$$

где $m_{n}$ - масса бюкса с образцом, г; $m_{1}-$ масса бюкса с образцом в абсолютно сухом состоянии, г; $m$ - масса бюкса, г. Взвешивание образцов проводили через $1,3,10,30$ суток.

Образцы, используемые для определения водопоглощения, через определённое время вынимали из эксикатора и измеряли их размеры в тангенциальном и радиальном направлениях с точностью до 0,01 мм. Затем по формулам $(2,3)$ определяли разбухание в тангенциальном и радиальном направлениях.

$$
\begin{aligned}
a_{t} & =\frac{L_{t \max }-L_{t \min }}{L_{t \min }} 100 \%, \\
a_{R} & =\frac{L_{R \max }-L_{R \min }}{L_{R \min }} 100 \%,
\end{aligned}
$$

где $L_{t \text { max }}, L_{R \text { max }}$ - размеры образца после выдерживания в воде 1, 10, 30 су- ток в тангенциальном $\left(L_{t \max }\right)$ и радиальном $\left(L_{R \min }\right)$ направлениях соответственно.

$L_{t \min }, L_{R \min }-$ размеры образца в абсолютно сухом состоянии в тангенциальном и радиальном направлениях соответственно.

Поверхностное натяжение древесины определяли по краевому углу смачивания. Для измерения краевого угла смачивания древесины использовали метод жидкой капли на поверхности твёрдого тела. На гладкую поверхность подложки в виде древесины берёзы наносили пипеткой каплю воды, выдерживали некоторое время до установления равновесия и проводили измерения с использованием диапроектора. Контур капли, помещённый между линзой и источником света, проектируют на экран и зарисовывают на листе бумаги. В точке соприкосновения трёх фаз проводят касательную и определяют краевой угол смачивания между касательной и твёрдой поверхностью. Для более точного определения краевого угла смачивания используют расчётный метод, согласно которому измеряют высоту капли жидкости, диаметр или радиус окружности смачивания.

\section{Обсуждение результатов}

Применяемые пропиточные составы обладали небольшой вязкостью, достаточной жизнеспособностью и легко проникали в структуры древесины. Пропиточные составы на основе отработанного растительного масла не имеют запаха и обладают экологической безопасностью для человека и животных.

На воздухе под действием кислорода, ультрафиолетового света и температуры растительные масла в поверхностном слое модифицированной древесины полимеризуются и твердеют. Это свойство связано с наличием в растительных маслах полиненасыщенных жирных кислот, таких как линолевая и линоленовая. Так как в подсолнечном масле таких кислот 
Таблица 1 Показатели водостойкости древесины берёзы

Table 1. Indicators of the water resistance of birch wood.

\begin{tabular}{|c|c|c|c|c|c|c|c|}
\hline \multirow{2}{*}{ Пропиточный состав } & \multirow{2}{*}{$\begin{array}{c}\text { Содержание } \\
\text { пропиточ- } \\
\text { ного состава } \\
\text { в древесине } \\
\%\end{array}$} & \multicolumn{3}{|c|}{$\begin{array}{c}\text { После 1суток нахожде- } \\
\text { ния в воде }\end{array}$} & \multicolumn{3}{|c|}{$\begin{array}{c}\text { После } 30 \text { суток } \\
\text { нахождения в воде }\end{array}$} \\
\hline & & $\mathrm{X}, \%$ & $\mathrm{Y}, \%$ & $Z, \%$ & $X, \%$ & $\begin{array}{l}\mathrm{Y}, \\
\%\end{array}$ & $\mathrm{Z}, \%$ \\
\hline Натуральная древесина & - & 63.6 & 9.65 & 7.80 & 100.8 & 9.65 & 7.80 \\
\hline $\begin{array}{l}\text { Чистое подсолнечное } \\
\text { масло }\end{array}$ & 35.2 & 21.8 & 6.87 & 5.83 & 49.3 & 8.64 & 6.93 \\
\hline $\begin{array}{c}\text { Отработанное подсол- } \\
\text { нечное масло }\end{array}$ & 36.6 & 21.3 & 7.49 & 6.10 & 48.9 & 9.28 & 7.02 \\
\hline $\begin{array}{c}\text { Отработанное подсол- } \\
\text { нечное масло + } 1 \text { \% дре- } \\
\text { весной муки }\end{array}$ & 43.5 & $19 . .1$ & 5.61 & 4.28 & 47.4 & 8.14 & 6.20 \\
\hline $\begin{array}{c}\text { Отработанное подсол- } \\
\text { нечное масло + } 1 \text { \% дре- } \\
\text { весной муки + } 1 \text { \% сик- } \\
\text { катива } \\
\end{array}$ & 36.4 & 32.1 & 8.05 & 6.33 & 51.1 & 7.97 & 5.92 \\
\hline $\begin{array}{c}\text { Отработанное подсол- } \\
\text { нечное масло + } 1 \text { \% дре- } \\
\text { весной муки + } 3 \% \text { сик- } \\
\text { катива }\end{array}$ & 55.4 & 13.2 & 5.12 & 3.75 & 35.2 & 8.71 & 6.38 \\
\hline $\begin{array}{c}\text { Отработанное подсол- } \\
\text { нечное масло + } 1 \text { \% сик- } \\
\text { катива с термообработ- } \\
\text { кой }\end{array}$ & 31.3 & 30.7 & 8.51 & 6.42 & 58.5 & 9.89 & 7.51 \\
\hline
\end{tabular}

$\mathrm{X}$ - водопоглощение, \%; Y - разбухание в тангенциальном направлении, \%; Z - разбухание в радиальном направлении, \%.

$\mathrm{X}$ - water absorption, \%; $\mathrm{Y}$ - swelling in the tangential direction, $\% ; \mathrm{Z}$ - swelling in the radial direction, $\%$

меньше, чем в других растительных маслах и процесс их затвердевания на воздухе протекает достаточно медленно, что требует введения в пропиточный состав сиккатива.

Показатели водостойкости древесины берёзы представлены в таблице 1.

Как следует из анализа полученных экспериментальных результатов, использование растительного масла как чистого, так и отработанного, существенно улучшает показатели водостойкости натуральной древесины. Так, водопоглощение обработанной древесины после 1 суток нахождения в воде снижается в три раза, а после 30 суток испытаний - более чем в два раза по сравнению с необработанной древесиной. Почти на 30 \% уменьшается разбухание древесины березы, пропитанной растительными маслами после 1 суток нахождения в воде. При длительном нахождении в воде этот эффект не так значителен.

Показателем эффективности процесса пропитки древесины служит количество введенного в поры древесины пропиточного состава. По этому показателю отработанное подсолнечное масло несколько превосходит растительное масло, не подвергавшееся температурному воздействию. Оно лучше проникает в поры древесины и остается в них, особенно в комбинации с древесной мукой и сиккативом. В случае термообработки модифицированной отработанным маслом древесины часть масла вытекает из её полостей, что сказывается на количестве введенного пропиточного состава а, следовательно, и на водопоглощении и разбухании обработанной древесины.

Показано, что наиболее оптимальным пропиточным составом на основе отрабо- 
Таблица 2. Значение краевого угла смачивания древесины берёзы в зависимости от пропиточного состава

Table 2. The value of the edge angle of wetting of the birch wood depending on the impregnating composition

\begin{tabular}{|l|c|}
\hline \multicolumn{1}{|c|}{ Пропиточный состав } & $\begin{array}{c}\text { Краевой } \\
\text { угол смачи- } \\
\text { вания }\end{array}$ \\
\hline Натуральная древесина & 15 \\
Чистое подсолнечное масло & 59 \\
Отработанное подсолнечное масло & 30 \\
Отработанное подсолнечное масло $+1 \%$ древесной муки & 29 \\
Отработанное подсолнечное масло $+1 \%$ древесной муки + $1 \%$ сиккатива & 55 \\
Отработанное подсолнечное масло $+1 \%$ древесной муки + 3\% сиккатива & 53 \\
Отработанное подсолнечное масло + 1 \% сиккатива с термообработкой & 59 \\
\hline
\end{tabular}

танного растительного масла для древесины березы является состав, содержащий $1 \%$ древесной муки и $3 \%$ сиккатива. Для таких образцов модифицированной древесины отмечено наибольшее количество введенного пропиточного состава и самые низкие значения водопоглощения и разбухания древесины в радиальном и тангенциальном направлениях.

Значение краевого угла смачивания древесины берёзы в зависимости от пропиточного состава представлены в таблице 2.

На основе анализа полученных данных можно сделать вывод, что обработка древесины отработанным растительным маслом позволяет в 2 раза увеличить краевой угол смачивания модифицированной древесины по сравнению с необработанной. Применение в пропиточном составе одной древесной муки в качестве наполнителя не приводит к увеличению защитных свойств поверхности древесины. Использование в пропиточном составе сиккатива совместно с древесной мукой позволяет снизить время высыхания и затвердевания поверхностной плёнки и улучшить водоотталкивающие свойства древесины ещё на 80\%. Увеличение дозировки сиккатива до 3\% не способствует снижению поверхностного натяжения получаемых образцов. Термообработка пропитанных образцов при температуре $150^{\circ} \mathrm{C}$ является дополнительным фактором повышения краевого угла смачивания модифицированной древесины.

\section{Заключение}

Разработанные составы на основе отработанного подсолнечного масла имеют низкую стоимость, обладают высокими показателями водостойкости, небольшой степенью разбухания в тангенциальном и радиальном направлениях, что позволит более эффективно защищать поверхность древесины от воды и расширить возможности применения древесных материалов в промышленности и быту.

При обработке древесины березы составами на основе отработанного растительного масла значительно сокращается число пор и уменьшается просвет капилляров древесного вещества, что подтверждается исследованием краевого угла смачивания поверхности древесины. Введенный в состав композиции наполнитель в виде древесной муки за счет процессов сорбции позволяет удерживать растительное масло в структурах древесины, повышая эффективность и защитные свойства пропиточного состава.

Внедрение предлагаемой технологии поможет утилизировать отход производства - отработанное растительное масло, что важно для защиты окружающей среды. 


\section{Список литературы}

1. Дмитренков А.И., Никулин С.С., Филимонова О.Н., Никулина Н.С. // Лесотехнический журнал. 2013. № 2. С.13-20.

2. Бельчинская Л.И., Жужукин К.В., Новикова Л.А., Дмитренков А.И и др. // Лесотехнический журнал. 2018. № 2. С.196-204.

3. Belchinskaya L.I., Zhuzhukin K.V., Dmitrenkov A.I., Novikova L.A. et al. // Forestry 2019. IOP Conference Series: Earth and Environ-mental Science. 2019. Vol. 392. 012075.

4. Cappelletto E., Maggini S., Girardi F. et al. // Cellulose. 2013. Vol. 20. pp. 3131-3141. https://doi.org/10.1007/s10570-013-0038-9.

5. Cappelletto E, Callone E, Campostrini R, Girardi F. et al,. // J Sol-GelSciTechnol. 2012. Vol.62 (3). pp. 441-452. DOI: 10.1007 / s10971012-2747-1

6. Lin W., Huang Y., Li J. et al. // Cellulose. 2018. Vol. 25. pp. 7341-7353. https://doi.org/10.1007/s10570-018-2074-y.

7. Kumar A., Ryparová P., Škapin A.S. et al. // Cellulose. 2016. Vol. 23. pp. 3249-3263. https://doi.org/10.1007/s10570-016-1009-8.

8. Croitoru C., Patachia S., Lunguleasa A. // Chemical Engineering Research and Design. 2015. Vol. 93. pp. 257-268.
9. Schwarzkopf M., Burnard, M., Tverezovskiy V. et al. // Eur. J. Wood Prod. 2018. Vol. 76. p. 1471-1482. https://doi.org/10.1007/s00107-0181336-6.

10. Rousset P., Perré P., Girard, P. // HolzRohWerkst. 2004. Vol. 62. pp. 113-125. https://doi.org/10.1007/s00107-003-0459-5.

11. Бельчинская Л.И., Дмитренков А.И., Жужукин К.В., Новикова Л.А. // «Комплексные проблемы техносферной безопасности» материалы Междунар. науч.-практ. конференции. Воронеж. 2017. Ч. III. С. 143-146.

12. Дмитренков А.И., Боровской А.М., Никулин С.С., Никулина Н.С. // «Наука и практика - 2019», материалы Всероссийской междисциплинарной научной конференции. 2019. Астрахань. С. 78-79.

13. Дмитренков А.И., Боровской А.М., Недзельская Е.А. // Академическая публицистика. 2019. № 12. С. 30-35.

14. Болоев П.А., Бураев М.К., Шистеев А.В., Бодякина Т.В. // Вестник ВСГУТУ. 2018. № 3 (70). C. 31-36.

15. Свидерский В.А., Токарчук В.В., Флейшер А.Ю. // Техника и технология силикатов. 2014. T. 21. № 3.C. 18-25.

\title{
Use of waste vegetable oil for the production of wood composites
}

\author{
(C) 2021 Dmitrenkov A.I., Khodosova N.A., Borovskoy M.A., \\ Nedzelskaya E.A., Zayats V.V.
}

Voronezh State University of Forestry and Technologies named after G.F. Morozov, Voronezh, Russian Federation

In the food industry, waste vegetable oils are formed in large quantities, remaining after the preparation of various food products. The disposal of waste oils is difficult and they pollute the environment. At the same time, in industry and everyday life, interest in natural wood as a natural renewable material does not decrease. However, the disadvantages of natural wood require its modification with various compositions. The study investigates the properties of birch wood impregnated with compositions based on waste vegetable oil. Vegetable oil left after cooking was used to impregnate the wood. Coniferous wood flour and a desiccant based on metal salts were used as fillers. The impregnating composition with a desiccant and a filler was heated to a predetermined temperature. Samples were placed in the pre-heated impregnating composition and kept for a certain time, then transferred to an impregnating composition with ambient temperature, where the impregnation was performed for the same amount of time. The impregnation was carried out by the hot-cold bath method. The properties of wood were controlled by changes in such indicators as water absorption, swelling in the radial and tangential directions, and the edge angle of wetting the wood surface. Impregnating compositions based on waste vegetable oil are odourless and environmentally friendly for humans and animals. It was noted that the use of vegetable oil, both pure and waste, significantly improves the water resistance of natural wood. The water absorption of treated wood after 1 day in water was reduced by three times, and after 30 days of testing, more than twice as compared to untreated wood. It has been shown that the most optimal impregnating composition based on waste vegetable oil for birch wood contained $1 \%$ wood flour and $3 \%$ desiccant. Thus, the treatment of birch wood with compositions based on waste vegetable oil allows not only the disposal 
of production waste, but also improvement of the properties of wood, such as water absorption, swelling in the tangential and radial directions.

Keywords: birch wood, modification, impregnation, water absorption, swelling, edge angle of wetting, vegetable oil.

\section{References}

1. Dmitrenkov A.I., Nikulin S.S., Fi-limonova O.N., Nikulina N.S., Lesotekhnicheskij zhurnal, 2013, No 2, pp.13-20.

2. Bel'chinskaya L.I., Zhuzhukin K.V., Novikova L.A., Dmitrenkov A.I. et al., Lesotekhnicheskij zhurnal, 2018, No 2, pp.196204.

3. Belchinskaya L.I., Zhuzhukin K.V., Dmitrenkov A.I., Novikova L.A. et al., Forestry, 2019. IOP Conference Series: Earth and Environ-mental Science, 2019, Vol. 392, 012075.

4. Cappelletto E., Maggini S., Girardi F. et al., Cellulose, 2013, Vol. 20, p. 3131-3141. https://doi.org/10.1007/s10570-013-0038-9.

5. Cappelletto E, Callone E, Campostrini R, Girardi F. et al, J Sol-GelSciTechnol., 2012, Vol. 62 (3), pp. 441-452. DOI: 10.1007 / s10971-0122747-1

6. Lin W., Huang Y., Li J. et al., Cellulose, 2018, Vol. 25, pp. 7341-7353. https://doi.org/10.1007/s10570-018-2074-y.

7. Kumar A., Ryparová P., Škapin A.S. et al. // Cellulose. 2016. Vol. 23. pp. 3249-3263. https://doi.org/10.1007/s10570-016-1009-8.

Дмитренков Александр Иванович - к.т.н., доцент кафедры химии, Воронежский государственный лесотехнический университет имени Г.Ф. Морозова, Воронеж

Ходосова Наталья Анатольевна - к.Х.н., доцент кафедры химии, Воронежский государственный лесотехнический университет имени Г.Ф. Морозова, Воронеж

Боровской Александр Михайлович - студент, Воронежский государственный лесотехнический университет имени Г.Ф. Морозова, Воронеж

Недзельская Екатерина Алексеевна - студент, Воронежский государственный лесотехнический университет имени Г.Ф. Морозова, Воронеж

Заяц Валентин Владимирович - студент, Воронежский государственный лесотехнический университет имени Г.Ф. Морозова, Воронеж
8. Croitoru C., Patachia S., Lunguleasa A., Chemical Engineering Research and Design, 2015, Vol. 93, pp. 257-268.

9. Schwarzkopf M., Burnard, M., Tvere-zovskiy V. et al., Eur. J. Wood Prod., 2018, Vol. 76, pp. 1471-1482. https://doi.org/10.1007/s00107018-1336-6. Odna stranitsa?

10. Rousset P., Perré P., Girard P., HolzRohWerkst, 2004, Vol. 62, pp. 113-125. https://doi.org/10.1007/s00107-003-0459-5.

11. Bel'chinskaya L.I., Dmitrenkov A.I., ZHuzhukin K.V., Novikova L.A., "Kompleksnye problemy tekhnosfernoj bezopasnosti» materialy Mezhdunar. nauch.-prakt. konferentsii. Voronezh, 2017, Ch. III, pp. 143-146.

12. Dmitrenkov A.I., Borovskoj A.M., Nikulin S.S., Nikulina N.S., "Nauka i praktika - 2019», materialy Vserossijskoj mezhdistsiplinarnoj nauchnoj konferentsii, 2019, Astrakhan', pp. 7879.

13. Dmitrenkov A.I., Borovskoj A.M., Nedzel'skaya E.A., Akademicheskaya publitsistika, 2019, No 12, pp. 30-35.

14. Boloev P.A., Buraev M.K., SHisteev A.V., Bodyakina T.V., Vestnik VSGUTU, 2018, No 3, (70), pp. 31-36.

15. Sviderskij V.A., Tokarchuk V.V., Flejsher A.YU., Tekhnika i tekhnologiya silikatov, 2014, Vol. 21, No 3, pp. 18-25.

Dmitrenkov Alexander I. - Ph.D. in Engineering, associate professor at Chemistry department of the Voronezh State University of Forestry and Technologies named after G.F. Morozov, Voronezh, e-mail: dmitrenkov2109@mail.ru

Khodosova Nataliya A. - Ph.D (chemistry), associate Professor at Chemistry department of the Voronezh State University of Forestry and Technologies named after G.F. Morozov, Voronezh, email: nhodosova@mail.ru

Borovskoy Alexander M. - student of the Voronezh State University of Forestry and Technologies named after G.F. Morozov, Voronezh

Nedzelskaya Ekaterina A. - student of the Voronezh State University of Forestry and Technologies named after G.F. Morozov, Voronezh, e-mail: Natursection@Gmail.com

Zayats Valentin V. - student of the Voronezh State University of Forestry and Technologies named after G.F. Morozov, Voronezh 